\title{
Herbal treatment effect on fabric thickness
}

Puspa, P. Punia and V. Singh

Received: 11.12.2017; Revised: 11.04.2018; Accepted: 01.05.2018

See end of the paper for authors' affiliations

\section{Puspa}

Department of Textile and Apparel Designing, College of Home Science, C.C.S. Haryana Agricultural University, Hisar (Haryana) India

Email : ptomer07@gmail.com
ABSTRACT : The present work was carried out with an objective to study the physical property of control and treated samples were tested to analyze the effect of Karanja extracts on the samples. The Shirley thickness tester was used to determine thickness of controlled', samples treated with both extracts of Karanja in both viscous and dry state; and antiseptic treated samples in both concentrations using BS 2544: 1967 test method. A specimen size of 5" $\times 5$ ". The tests were performed for different types of samples viz., control (scoured), samples treated with leaves and seed extracts in viscous and dry state; and samples treated with an antiseptic containing chloroxylenol. The samples were subjected to test for fabric thickness (mm). It was concluded that as the concentration of extract increased, thickness ( $\mathrm{mm}$ ) of all treated samples increased significantly. A $1 \%$ level significant increase in thickness ( $\mathrm{mm}$ ) was observed in all treated samples as compared to the control sample.

KEY WORDS: Extract, Antiseptic, Viscous, Thickness, Chloroxylenol

- HOW TO CITE THIS PAPER : Puspa, Punia, P. and Singh, V. (2018). Herbal treatment effect on fabric thickness. Asian J. Home Sci., 13 (1) : 275-279, DOI: 10.15740/HAS/AJHS/13.1/275-279. Copyright@ 2018: Hind Agri-Horticultural Society. 